\title{
Current applications and future prospects of nanomaterials in tumor therapy
}

\author{
This article was published in the following Dove Press journal: \\ International Journal of Nanomedicine \\ 7 March 2017 \\ Number of times this article has been viewed
}

\author{
Yu Huang' \\ Chao-Qiang Fan' \\ Hui Dong' \\ Su-Min Wang' \\ Xiao-Chao Yang ${ }^{2}$ \\ Shi-Ming Yang' \\ 'Department of Gastroenterology, \\ Xinqiao Hospital, Third Military \\ Medical University, Chongqing, \\ People's Republic of China; \\ ${ }^{2}$ Department of Biomedical Materials \\ Science, School of Biomedical \\ Engineering, Third Military Medical \\ University, Chongqing, People's \\ Republic of China
}

\begin{abstract}
Tumors are one of the most serious human diseases and cause numerous global deaths per year. In spite of many strategies applied in tumor therapy, such as radiation therapy, chemotherapy, surgery, and a combination of these treatments, tumors are still the foremost killer worldwide among human diseases, due to their specific limitations, such as multidrug resistance and side effects. Therefore, it is urgent and necessary to develop new strategies for tumor therapy. Recently, the fast development of nanoscience has paved the way for designing new strategies to treat tumors. Nanomaterials have shown great potential in tumor therapy, due to their unique properties, including passive targeting, hyperthermia effects, and tumor-specific inhibition. This review summarizes the recent progress using the innate antitumor properties of metallic and nonmetallic nanomaterials to treat tumors, and related challenges and prospects are discussed.
\end{abstract}

Keywords: tumor, nanomaterials, nanoparticles, nanotechnology

\section{Introduction}

The development of tumors occurs at the molecular level ${ }^{1}$ when multiple subgroups of genes undergo genetic alterations. Either tumor-suppressor genes are inactivated or oncogenes are activated, which leads to malignant proliferation of tumor cells, tissue infiltration, and organ dysfunction. ${ }^{2}$ Many methods have been developed for tumor therapy, such as immunotherapy, ${ }^{3,4}$ gene therapy, ${ }^{5,6}$ and radiofrequency ablation (RFA). ${ }^{7-9}$ Nevertheless, traditional radiotherapy, ${ }^{10,11}$ surgery, ${ }^{12-14}$ and especially chemotherapy ${ }^{15,16}$ are still the major strategies utilized in clinical tumor treatments. However, chemotherapy has a number of problems, including nonspecific distribution of the drug and the lack of tumor-specific treatments. ${ }^{17}$ In the continuous fight against tumors, patients have to be administered drugs that increase in dose over time, which is associated with considerable adverse effects, such as multidrug resistance and accumulative systemic toxicity. Chemotherapy also causes side effects in healthy tissues, which have negative impacts on the quality of life of the patients. ${ }^{18,19}$ In addition, chemotherapy may concomitantly damage adjacent organs or tissues, and these adverse effects are difficult to avoid. ${ }^{20,21}$

In recent decades, the development of nanotechnology has provided an opportunity to overcome the aforementioned side effects. The integration of various nanomaterials (NMs) with spectroscopic, biochemical, and optical methods has allowed the development of advanced methods for tumor therapy, which may revolutionize the treatment of tumors. An emerging approach is to utilize nanotechnology and NMs to minimize toxicity to healthy tissues. Various NMs have performed attractively in various aspects of antitumor treatment and garnered intense research interest, and 


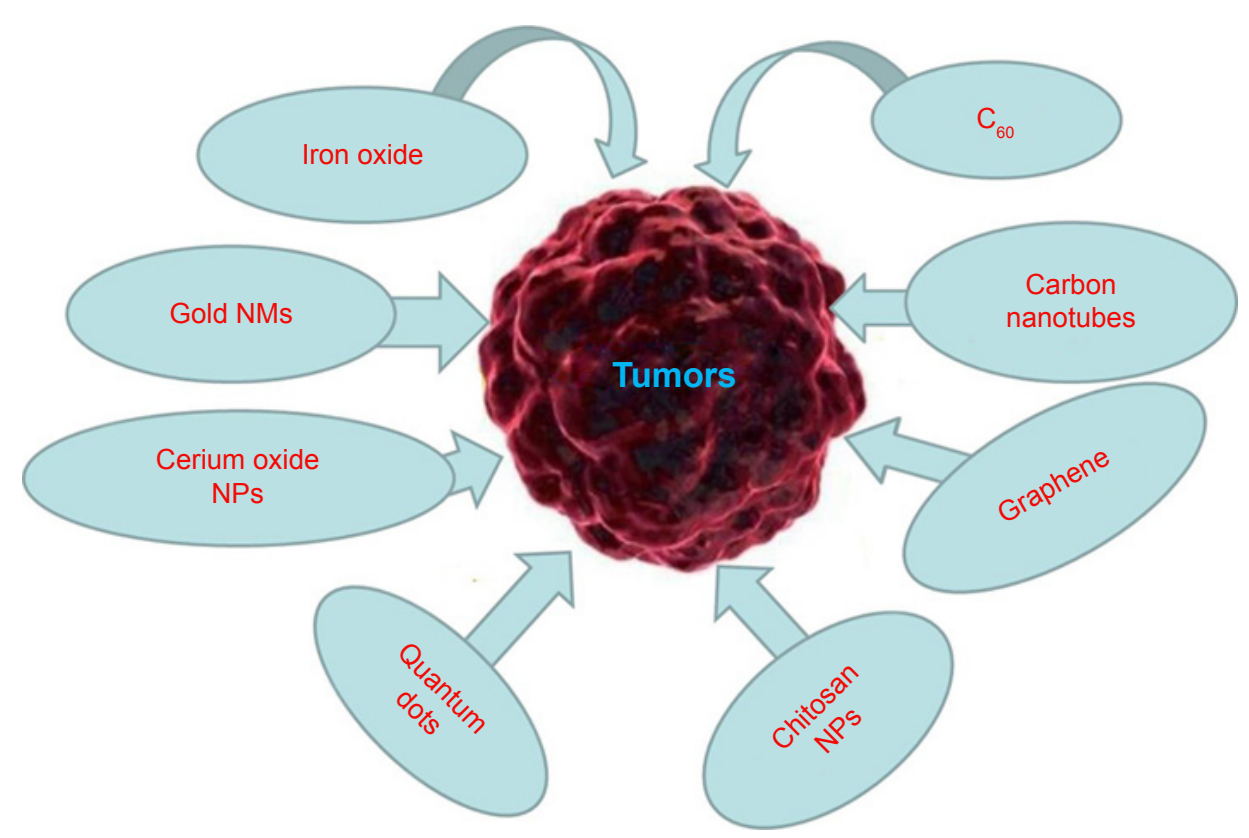

Figure I Metallic and nonmetallic nanomaterials that act as active medicine or drug additive in tumor therapy through their innate antitumor properties. Abbreviations: NMs, nanomaterials; NPs, nanoparticles.

they have presented great potential for antitumor treatment by enhancing the effectiveness of treatments and reducing systemic side effects.

The term "nano-" is derived from the Greek noun nanos, ${ }^{22}$ and a nanometer $(\mathrm{nm})$ is equivalent to $10^{-9} \mathrm{~m} .{ }^{23}$ The specific physical and/or chemical properties of NMs make them very attractive in biomedical applications..$^{24,25}$ Over the past few decades, the explosion of studies involving NMs can be ascribed to their special optical, thermodynamic, magnetic, and mechanical properties. ${ }^{26-28}$ Potential medical applications of NMs have been recognized to have good biocompatibility. ${ }^{29}$ Nanoparticles (NPs) with suitable diameter range have been reported to be able to enter blood circulation and undergo endocytosis into cells. ${ }^{30}$ Furthermore, scientific research shows that NM-based therapeutics have great potential in the treatment of tumors, diabetes, infection, neurodegenerative disease, and inflammation. ${ }^{31-33}$ The integration of tumor therapy with NMs is expected to bring about new breakthroughs for nanotechnology in the field of medicine.

The physical and chemical properties of NMs impact on biodistribution, cellular processes, and cytotoxic effects. ${ }^{27,34,35}$ For example, the size of the NM affects cellular tropism by facilitating or inhibiting actin polymerization. ${ }^{36}$ In addition to size, the shape of NMs influences organ and cellular tropism. ${ }^{37}$ Spherical NMs promote phagocytosis of macrophages, but disk-shaped structures do not. By tailoring these aspects, specific properties of NMs can be used to design new biomedical applications, which include various clinical and research activities and modulation of processes in target cells. ${ }^{38}$ With the development of nanotechnology, the integration of NMs into tumor therapeutics is one of the rapidly advancing fields, and more new NMs will be increasingly used in the field of tumor treatment.

Based on nanotechnology, various NMs have been developed, such as iron oxide NPs, gold NPs (AuNPs), cerium oxide NPs, carbon-based materials, polymeric NPs, and quantum dots (QDs). ${ }^{39-44} \mathrm{NMs}$ have shown great potential in tumor prevention, detection, diagnosis, imaging, and treatment. Due to their specific physical, chemical, and biological properties and unique structure, NMs are able to work at the molecular level. Therefore, NMs themselves are antigenic or medicinally active, and can stimulate a strong immune response in the body. ${ }^{45}$ Some NMs can kill or inhibit pathogenic cell types by exploiting their autoimmunity or cellular toxicity (selective block by toxicity). ${ }^{46-48}$ Various NMs themselves are used as potential antitumor drugs, and are being developed as photothermal therapy (PTT) agents. ${ }^{49,50}$ Therefore, this review discusses some specific metallic NMs (MNMs) and nonmetallic NMs that act as a medicine or drug additive in tumor therapy (Figure 1).

\section{Metallic NMs}

MNMs are metal or metal oxide nanocrystals. MNMs are readily prepared, have surfaces relatively easy to modify, and in general have low toxicity. ${ }^{51,52}$ Because of their unique properties, the advantage of using MNMs lies primarily in 
their ability to interact directly with cell membranes and intracellular structures. ${ }^{41,42}$ As discussed earlier, these special properties make MNMs useful for numerous diagnostic and therapeutic applications. ${ }^{53}$ Most MNMs for tumor therapy consist of iron oxide, gold NPs, and cerium oxide NPs (Figure 2). ${ }^{54-57}$

\section{Iron oxide}

Iron oxide is a type of magnetic material that is used in tumor PTT and targeted therapy. PTT is based on using optical heating to facilitate direct and specific destruction of tumor cells. ${ }^{58}$ PTT is a highly promising approach to tumor therapy. Phototherapy employs near-infrared light (NIR)-absorbing agents with high absorption in the NIR region, which then release vibrational energy (heat) to kill the targeted tumor cells.
$\mathrm{Fe}_{3} \mathrm{O}_{4}$-based magnetic NPs are recognized as promising hyperthermia-specific agents. To treat metastatic bone tumors, Matsumine et $\mathrm{al}^{59}$ used novel $\mathrm{Fe}_{3} \mathrm{O}_{4}$ powder for hyperthermia-induced apoptosis in several patients. One week later, after incorporating $\mathrm{Fe}_{3} \mathrm{O}_{4}$ in the adhesive that repaired the bone, patients were subjected to a localized electromagnetic field at a temperature estimated to be $40^{\circ} \mathrm{C}-45^{\circ} \mathrm{C}$, in order to improve the lesion. This treatment stopped further metastatic progression, and demonstrated the benefit of using iron oxide in bone-tumor treatments.

In addition to PTT, potential medical applications of magnetic NPs have also been approved, due to their good biocompatibility. ${ }^{26}$ According to a recent report, magnetic NPs with diameters ranging between several $(\sim 9 \mathrm{~nm})$ and hundreds $(\sim 200 \mathrm{~nm})$ of nanometers can circulate in blood
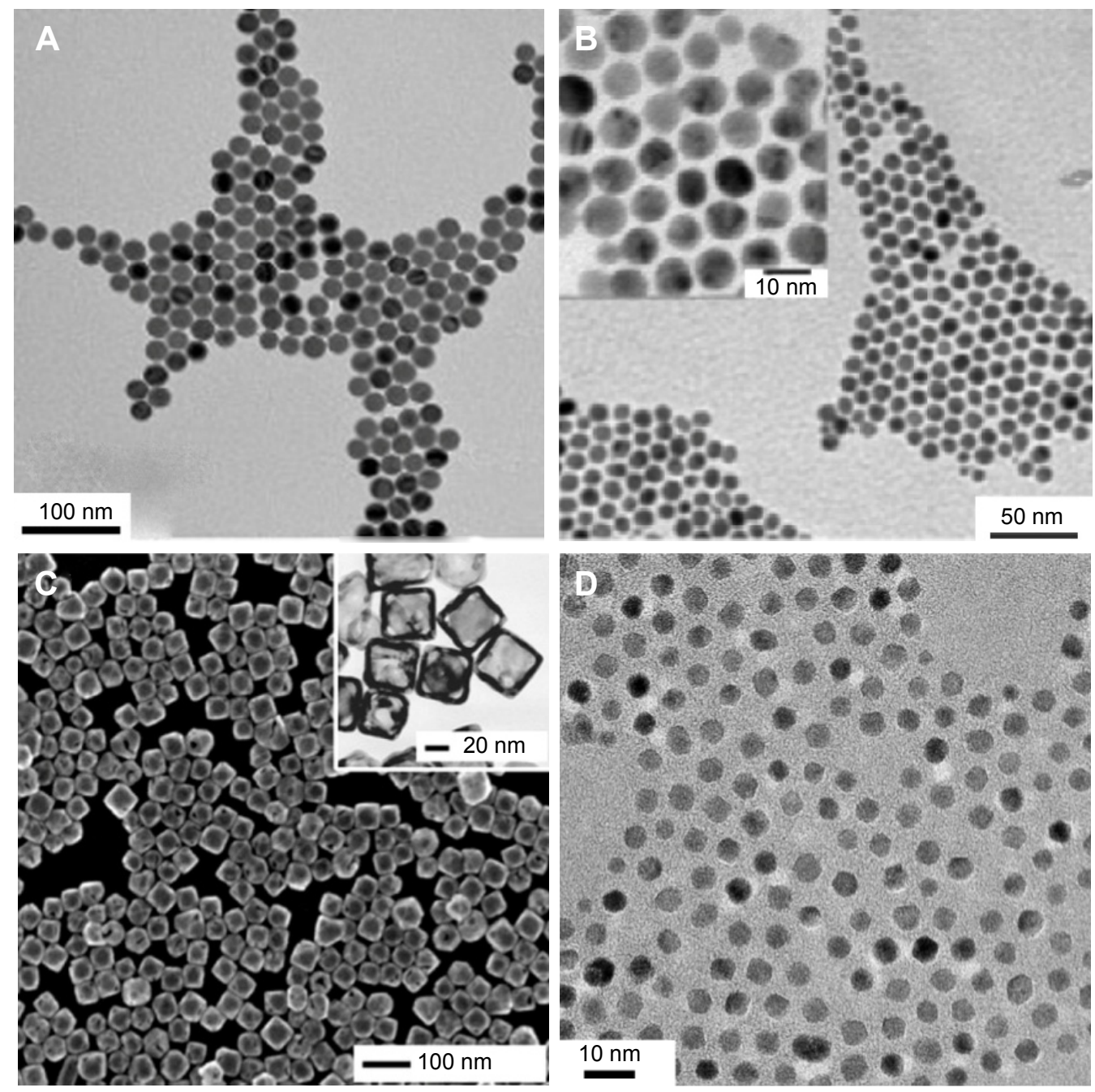

Figure 2 Transmission electron microscope images of (A) iron oxide nanoparticles; (B) gold nanoparticles; (C) gold nanocages; (D) cerium oxide nanoparticles. Notes: Figure $\mathbf{A}$ adapted with permission from Bronstein LM, Huang XL, Retrum J, et al. Influence of iron oleate complex structure on iron oxide nanoparticle formation. Chem Mater. 2007;19(15):3624-3632. Copyright @ 2007, American Chemical Society. ${ }^{54}$ Figure B adapted with permission from Schulz-Dobrick M, Sarathy KV, Jansen M. Surfactantfree synthesis and functionalization of gold nanoparticles. J Am Chem Soc. 2005; 127(37): 12816-12817. Copyright @ 2007, American Chemical Society. ${ }^{55}$ Figure C adapted with permission from Chen JY, Wang DL, Xi JF, et al. Immuno gold nanocages with tailored optical properties for targeted photothermal destruction of cancer cells. Nano Lett. 2007;7(5): 13 18-1322. Copyright (C) 2007, American Chemical Society. ${ }^{56}$ The method reported in Lee et al ${ }^{57}$ was used when creating the nanoparticles shown in Figure D. 
vessels and undergo endocytosis into cells. ${ }^{60}$ The authors also found that dimercaptosuccinic acid-coated iron oxide NPs have excellent potential for applications that target breast-tumor cells.

Furthermore, $\mathrm{Fe}_{3} \mathrm{O}_{4}$ NPs can be functionalized using antibodies and achieve active targeted tumor therapy. There is a report of using anti-HER2-conjugated polypyrrole- $\mathrm{Fe}_{3} \mathrm{O}_{4} \mathrm{NPs}$ to target and damage SK-BR-3 breast tumor cells in vitro. ${ }^{61}$ In fact, superparamagnetic iron oxide NPs (SPIONs; $\mathrm{Fe}_{3} \mathrm{O}_{4}$ or $\left.\mathrm{Fe}_{2} \mathrm{O}_{3}\right)^{62}$ have been recognized for clinical use in the form of ferucarbotran (carboxydextran SPIONs), ferumoxides (dextran SPIONs), and ferumoxtran 10 (dextran SPIONs). ${ }^{63}$ These SPIONs are highly biodegradable and biocompatible; the iron core is recycled into soluble ferritin iron or hemosiderin. ${ }^{64}$ Iron oxide NPs are also intensively used in imaging system as contrast agents in pathophysiological studies. ${ }^{65}$

\section{Gold NMs}

In recent years, AuNMs have shown important potential in various biomedical and research applications, such as catalysis, bioanalysis, and imaging. ${ }^{66,67}$ The preparation technology is simple, and it is easy to control the size and shape of AuNMs. ${ }^{68,69}$ It has been reported that AuNMs can selectively and specifically recognize tumor cells. ${ }^{70,71}$ Studies reported in the literature have shown that AuNMs are easily functionalized, increase the time of circulation, and are stable in systemic circulation. In addition, AuNMs have low toxicity and protect drugs from potential transformation in tissues and organs. Perhaps the most important property of AuNMs is their ability to destroy tumor cells. ${ }^{72}$ Thus, such AuNMs as AuNPs ${ }^{73,74}$ and gold nanocages ${ }^{56}$ are a promising tool for selectively killing tumor cells through photothermal (PT) damage.

AuNPs can enhance the apoptotic effect of tumors, ${ }^{7}$ which makes it possible to decrease radiation doses, thereby reducing side effects on surrounding normal tissues. AuNPs can also enhance the effect of radiotherapy, which has been verified in vivo and in vitro in animal models of tumors. ${ }^{72}$ AuNPs are commonly used as nanobioconjugates. ${ }^{69,70,73}$ The functionalization of NPs (eg, with polyethylene glycol [PEG] or antibodies) allows the nanobioconjugates to remain in the bloodstream and preferentially accumulate in tumor tissue. These nanobioconjugates have the ability to penetrate the cell nucleus, increasing the likelihood that the active cytostatic substance acts directly on DNA. ${ }^{74}$ Studies reported in the literature have shown that multifunctional AuNPs can be used both to image and treat tumors. ${ }^{70}$

RFA is a novel therapeutic method for the treatment of tumors. This method uses imaging guidance to place a needle electrode either through the skin or directly (during surgery) into the pathological tissue. High-frequency electrical currents pass through the electrode and create heat that destroys tumor cells. AuNPs have been used in this field, making it possible to destroy tumor cells noninvasively by RFA. ${ }^{12-14}$ The optical properties of nanoshells can be utilized in tumorablation techniques with NIR light or RFA. Laroui et al developed nanoshells coated with gold, absorbing specific wavelengths of light. ${ }^{75}$ Fortina et al synthesized nanoshells linked to a ligand. ${ }^{76}$ Citrate-coated gold has been shown to have antitumor properties. ${ }^{77,78}$

Xia et al $^{56}$ synthesized novel gold nanocages $\sim 45 \mathrm{~nm}$ in edge length. These gold nanocages have shown potential for targeted PT inhibition of tumor cells. The nanocages were designed to convert $810 \mathrm{~nm}$ NIR light to heat via a large absorptive cross section of $3.48 \times 10^{-14} \mathrm{~cm}^{2}$, and strongly absorbed light in the NIR region. PT studies of the nanocages showed that the PT cell-damage power-density threshold was $1.5 \mathrm{~W} / \mathrm{cm}^{2}$, which is lower than that of gold nanoshells $\left(35 \mathrm{~W} / \mathrm{cm}^{2}\right)$ and gold nanorods $\left(10 \mathrm{~W} / \mathrm{cm}^{2}\right)$. By conjugating the nanocages with monoclonal antibodies (anti-HER2), the nanocages can target epidermal growth factor receptors (EGFRs) that are overexpressed on the surface of breasttumor cells. These results indicated that shape- and sizemodulated AuNMs could be potential tumor PTT reagents.

\section{Cerium oxide nanoparticles}

Cerium oxide NPs include a cerium core surrounded by an oxygen lattice. ${ }^{79}$ In normal cells, these NPs have an antioxidant and cytoprotective role under neutral $\mathrm{pH}$. In an acid medium, which is one of the characteristics of tumor cells, these NPs show prooxidant and cytotoxic effects. Pei et al studied the antitumor effects of cerium oxide NPs in in vitro models, and the results showed that cerium oxide NPs inhibited the growth of tumor cells. ${ }^{80}$ There has been another report indicating that a high concentration $(10 \mu \mathrm{g} / \mathrm{mL})$ of cerium oxide NPs can suppress tumor-cell migration and inhibit tumor-cell proliferation. ${ }^{81}$

\section{Quantum dots}

Another popular type of NM are QDs. ${ }^{40}$ QDs are very small nanocrystals that emit fluorescence when stimulated by a specific wavelength of light, and their diameter is approximately 2-10 nm. ${ }^{44,82,83}$ Their structure consists of an inorganic core and shell, which can be modified with biological molecules, such as PEG. ${ }^{84}$ Their emission and absorption properties can be controlled precisely by modulating their size and shape. ${ }^{85}$ The benefit of QDs for tumor therapy is attributed to their mechanisms of photosensitization and radiosensitization. 
With electronic energy levels in the $1-5 \mathrm{keV}$ range, QDs can be used as photosensitizers for photodynamic treatments, which have become an approved therapy modality for some types of tumors. Because of their high electron and atom density, QDs act as radiosensitizers that absorb high-energy photons and cause localized or targeted damage to tumor cells. ${ }^{86}$

\section{Nonmetallic NMs}

There are several different types of nonmetal NMs (Figure 3), and carbon compounds are some of the most extensively studied. Several different "pure" carbon-based constructs have been studied, such as fullerenes and their derivatives, which are composed of carbon atoms arranged in a spherical shape called a truncated icosahedron, and carbon nanotubes (CNTs), which are most frequently studied in biological systems. ${ }^{3,87}$ Fullerenes and their derivatives are readily accessible to cells, and are conjugated with various therapeutic molecules because they have a unique nanostructure. In addition, the pure carbon composition of fullerenes gives them good biocompatibility. Moreover, carbon NMs have been linked with biological molecules and polymers, and so can be effectively used for antitumor applications in vivo. ${ }^{40}$ Therefore, functional fullerenes and their derivatives can be linked to a wide variety of active molecules to target tumor cells..$^{87,88}$ Based on these experiments, fullerenes and their derivatives have become a new class of promising candidates for tumor treatments. This portion of the review attempts to provide insight into the progress of the use of fullerenes and their derivatives as tumor-therapy drugs.

A

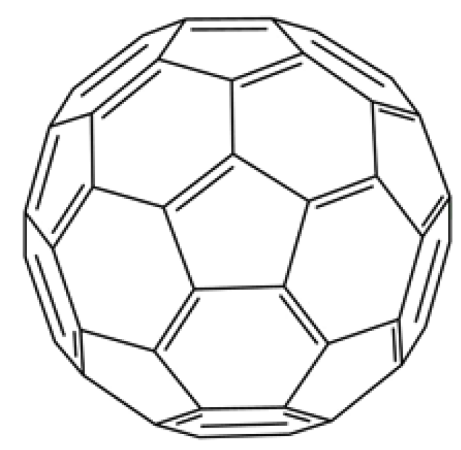

C

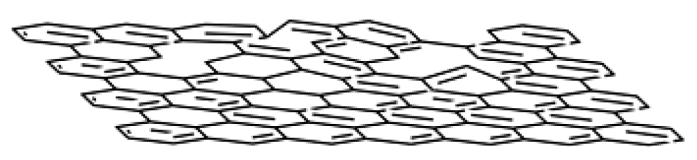

$\mathrm{C}_{60}$

$\mathrm{C}_{60}$ (or "bucky-ball" $\mathrm{C}_{60}$ ) is a hollow sphere with a diameter of $1 \mathrm{~nm}$, and is made up of 60 carbon atoms. $\mathrm{C}_{60}$ is effective in terms of interactions with the immune system, and has dramatic potential as an antitumor drug. Compared with conventional antitumor chemicals, fullerenes and their derivatives are more efficient at inhibiting the growth of tumors. The result is not due to toxic effects on tumor cells, but the fullerenes, which have almost no toxicity in vivo or in vitro, have a strong ability to enhance immunity and protect normal tissues from tumor invasion. ${ }^{89,90}$

Endohedral metallofullerenes (fullerenes encapsulating a metal atom) have shown dramatic potential for biomedical applications. For example, Hirahara et al ${ }^{11}$ synthesized a multihydroxylated fullerene - $\mathrm{Gd} @ \mathrm{C}_{82}(\mathrm{OH})_{22}$. Compared with some other clinical antitumor drugs, $\mathrm{C}_{60}(\mathrm{OH})_{20}$ and $\mathrm{Gd} @ \mathrm{C}_{82}(\mathrm{OH})_{22}$ NPs are highly effective at suppressing tumor growth in mice with negligible side effects. The high antitumor activity may be because the water-soluble NMs can effectively trigger the host immune system to eliminate tumor cells and regulate the angiogenesis and oxidative defense system in vivo. ${ }^{92}$

\section{Carbon nanotubes}

CNTs are coaxial graphite layers with cylinders..$^{93}$ CNTs are formed by polymerization of single carbon atoms under specific conditions. ${ }^{94}$ According to their structure, CNTs can be divided into two categories: single-walled CNTs (SWCNTs) and multiwalled CNTs (MWCNTs). The former is a single cylindrical carbon wall, and the latter is an MW

B

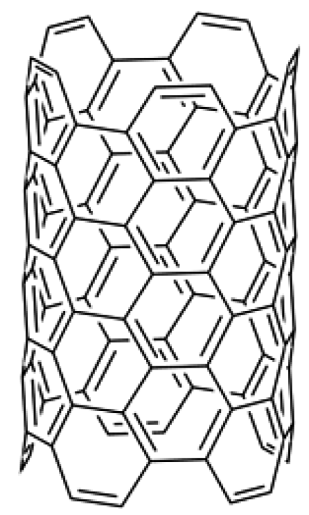

D

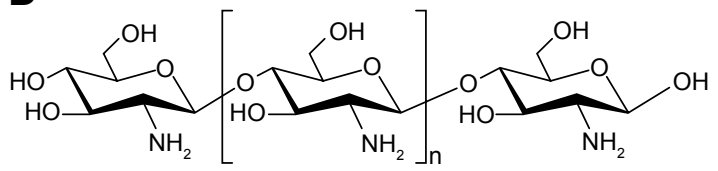

Figure 3 Structures of nonmetallic nanomaterials for tumor therapy.

Notes: (A) $\mathrm{C}_{60}$; (B) carbon nanotubes; (C) graphene; (D) chitosan-structure units $\beta$-(I,4)-2-amino-D-glucose and $\beta$-(I,4)-2-acetamido-D-glucose. 
cylinder nested in other cylinders. ${ }^{95}$ With the development of nanotechnology, integration of CNTs into tumor therapeutics is a rapidly advancing field..$^{96,97}$ There are reports that CNTs promote the phagocytosis of dendritic cells at tumor sites, which produce more antigens to dendritic cells, significantly increasing the immunogenicity of proteins in the tumor. ${ }^{98}$ Similarly, inhaled CNTs can inhibit lung-resident dendritic cells and promote lung immune suppression. ${ }^{47}$ Regarding the direct therapeutic effect, CNTs can induce tumor-tissue destruction by PTT, based on strong optical absorbance under NIR-light excitation. ${ }^{99,100}$ Therefore, CNTs have attracted interest as efficient PTT agents for tumor treatments. ${ }^{101-103}$ Hyperthermia therapy is another type of optional solution for tumor treatment, especially for some solid malignant tumors, such as breast and liver tumors. CNTs are also used as PT tumor-ablation mediators. ${ }^{100}$ Due to the thermal conductivity and optical properties of CNTs, they have become mediators to optically stimulate NTs that are placed inside living cells and that kill tumor cells via local hyperthermia.

There has been much research to show the feasibility of CNTs in the treatment of malignant tumors. SWCNTs are promising candidates as a PTT agent, because they also have high absorption in the NIR spectrum, which is ideal for inducing PT damage to tumor cells or tissues. Continuous NIR radiation can lead to cell death, because of excessive local heating of SWCNTs. Kam et a ${ }^{104}$ showed that this approach is effective. In a similar work, ${ }^{105}$ the authors showed that HER2-IGFR-SWCNTs were able to destroy all targeted tumor cells. MWCNTs also efficiently absorb NIR light and efficiently convert the absorbed energy into thermal energy. MWCNTs can be stimulated with NIR irradiation to damage cervical tumor HeLa cells ${ }^{106}$ and EAC cells. ${ }^{107}$ CNTs make it possible to damage tumor cells noninvasively, and the potential applications for CNTs in tumor therapy have attracted much clinical interest. Therefore, CNTs can be considered another class of tumor PTT system, and are highly promising for clinical trials.

\section{Graphene}

Graphene is an emerging NM with single-layered carbon atoms in a two-dimensional honeycomb structure. Graphene has attracted great interest since its tremendous groundbreaking discovery in 2004. ${ }^{108-110}$ Graphene and its different subtypes, such as graphene oxide (GO) and reduced graphene oxide (RGO), have been extensively studied in the realm of nanomedicine, due to their exceptional physical, chemical, and mechanical properties. ${ }^{111}$ Graphene-based NMs have a well-described role in tumor management. ${ }^{112}$ Graphene-based NMs are used mainly for PTT.

Yang et $\mathrm{al}^{113}$ reported that PEGylated GO (GO-PEG) showed highly efficient tumor ablation under NIR-light irradiation, and GO-PEG was used for in vivo PTT. These authors noticed that GO-PEG had no obvious side effects, and was safe during the treatment. In a follow-up study, Yang et $\mathrm{al}^{114}$ verified that PEGylated nano-RGO (nRGO-PEG) with an ultrasmall average diameter of $\sim 27 \mathrm{~nm}$ was a better NM than GO for PTT with low-power laser irradiation. The in vivo PTT study demonstrated that nRGO-PEG was more efficient in tumor ablation and that NIR laser-power density was greatly reduced. These results indicated that nRGOPEG strongly absorbs light in the NIR region $(808 \mathrm{~nm})$, with an intensity threshold of $0.15 \mathrm{~W} / \mathrm{cm}^{2}$, to induce thermal destruction of tumor cells. There have been some studies that reported that nanoparticles such as AuNPs, ${ }^{115,116} \mathrm{AgNPs},{ }^{117}$ copper monosulfide NPs, ${ }^{118}$ and copper(I) oxide NPs ${ }^{119}$ attached to the surface of GO synergistically enhanced PTT. These results highlight that both the size and surface chemistry of GO are critical to the effectiveness of in vivo PTT, which indicates that optimized nanographene could be a PTT reagent for treating tumors.

\section{Chitosan nanoparticles}

Chitosan is a type of cationic oligosaccharide that is the major component of the exoskeleton of crustaceans and insects. ${ }^{120}$ Chitosan is a biopolymer containing $\beta$ - $(1,4)$ 2-amino-D-glucose and $\beta$ - $(1,4)-2$-acetamido-D-glucose units. ${ }^{73}$ Chitosan NPs (ChNPs) are obtained by deacetylation, which removes an acetate moiety from chitin. ChNPs are primarily degraded in the colon by the action of lysozyme and bacterial enzymes, and are finally eliminated in the feces. Chitosan is a natural polysaccharide that has excellent biocompatibility, biosecurity, biodegradability, and nontoxic characteristics. ${ }^{121,122}$ ChNPs are commonly modified with epichlorohydrin and PEG dicarboxylic acid. ${ }^{123,124}$ ChNPs also have dramatic potential for tumor therapy.

ChNPs can directly affect the metabolism of tumor cells by inducing apoptosis and inhibiting cellular growth. Likewise, ChNPs play a role in increasing the immune function of the organism by facilitating the contact between the drug and the tumor-cell membrane. ${ }^{125,126}$ Reports show that ChNPs have high stimulatory activity on B and T lymphocytes and the humoral immune system, which can be activated at the same time.${ }^{127} \mathrm{ChNPs}$ also have a strong immunostimulating 
effect by increasing the activation and accumulation of polymorphonuclear and macrophage cells, and they induce cytokine production after intravenous injection. ${ }^{128,129}$ There is another example that indicates that ChNPs have their own antitumor effects. ChNPs themselves have a positive charge; therefore, they can neutralize the negative charges on the surface of tumor cells, which has a tendency to contribute to their selective uptake. In this way, ChNPs can effectively inhibit proliferation of tumor cells by increasing the concentration of cytostatic agents at the tumor sites. ${ }^{130}$ All these attributes and examples show that ChNPs have great potential in tumor therapy.

\section{Challenges and future perspectives}

Over the last 20 years, NMs have come to play a significant role in commercial development. Indeed, we might expect to produce many breakthroughs and new prospects for the world economy from advances in nanotechnology. With the potentially wide application of NMs in the future, NMs may be extensively used in various fields, especially tumor therapy. NMs can be used for clinical diagnosis and tumor therapy, based on their size, biocompatibility, surface chemistry, relatively good stability, and adjustable toxicity in biological systems. It is highly expected that the application of NMs in tumor therapy will greatly improve current methods of tumor-cell detection, tumor imaging, and tumor therapy, while reducing toxicity compared to traditional tumor treatments.

However, there are several challenges in the field, and there are still controversies about the potential risk of antitumor therapies. The most pressing problems are potential chronic and acute toxic effects; the potential toxicity of NMs cannot be ignored in antitumor therapy. ${ }^{131}$ There have been reports on the toxicity of NMs. NMs may be attached to the surface of biological membranes by adsorption or electrostatic interactions, and they can cause damage to cells by producing reactive oxygen species, leading to protein denaturation, lipid peroxidation, DNA damage, and ultimately cell death. ${ }^{132-134}$ For instance, NPs and CNTs can damage the respiratory and cardiovascular systems, ${ }^{135,136}$ and they can enter the central nervous system through the blood-brain barrier, resulting in a variety of nervous system diseases. ${ }^{137-139}$ In vitro studies have shown that CNTs can induce cell apoptosis, decrease cell viability, and disrupt the cell cycle and inflammatory responses. ${ }^{140-142}$ It has been confirmed that CNTs can damage lung tissue ${ }^{143}$ and that they are toxic to the immune system in mice. ${ }^{46}$ Besides, the blood incompatibility of CNTs also limits their use in the clinic. Although many studies have shown that the functionalization of CNTs can improve their water-solubility, proof of their biocompatibility and safety is currently insufficient. For example, $\mathrm{Li}$ et al ${ }^{144}$ reported that sugar-functionalized SWCNTs formed stable homogeneous aqueous solutions, Barzegar et $\mathrm{al}^{145}$ reported that noncovalent functionalized SWCNTs could also improve the water solubility of SWCNTs, and Ali et al ${ }^{146}$ functionalized SWCNTs with the TGAD enzyme to render SWCNTs soluble in a plethora of solvents. However, the biocompatibility of functionalized SWCNTs was not evaluated in these studies. When QDs are applied in the body, their toxicity cannot be ignored, because they may contain heavy metals. It is necessary to carry out a detailed toxicity study to ensure safety prior to further applications in humans. Further research will not be conducive to the clinical application of NMs and industrial production unless the toxicity problem is resolved. In addition, only a few types of materials have been approved by the US Food and Drug Administration, and very few NMs have been approved as antitumor agents to enter Phase III clinical trials or enter the market, which indicates that NMs need to be understood more deeply before their potential application in tumor therapy.

Therefore, the long-term toxicity of NMs to living systems needs to be intensively studied. There is an article that analyzes the possible toxicological implications of NMs in nanomedicine. The authors believed that it is necessary to research the mechanisms of injury in cells due to NMs extensively before NMs can be used in tumor treatments. ${ }^{147}$ Development of tumor therapies is a multidisciplinary field, and with more in-depth research on tumor biology, tumor immunology, molecular biology, and NMs, an ideal therapy or NM will eventually be produced for the treatment of tumors. The conversion of nanotechnology to routine clinical practice will require a multidisciplinary approach guided by clinical, ethical, and social perceptions. In view of the significant research results being dedicated to the field, it may be expected that humans will greatly benefit from nanotechnology and NMs in the very near future, especially in tumor therapy.

\section{Acknowledgment}

This study was supported by the Chongqing Science \& Technology Commission of China (cstc2016shmszx0915).

\section{Disclosure}

The authors report no conflicts of interest in this work. 


\section{References}

1. Steven A, Seliger B. Control of CREB expression in tumors: from molecular mechanisms and signal transduction pathways to therapeutic target. Oncotarget. 2016;7(23):35454-35465.

2. Sarkar FH, Banerjee S, Li YW. Pancreatic cancer: pathogenesis, prevention and treatment. Toxicol Appl Pharm. 2007;224(3):326-336.

3. Tang HD, Qiao J, Fu YX. Immunotherapy and tumor microenvironment. Cancer Lett. 2016;370(1):85-90.

4. Li B, Li TW, Pignon JC, et al. Landscape of tumor-infiltrating T cell repertoire of human cancers. Nat Genet. 2016;48(7):725-732.

5. Luo JF, Luo YX, Sun JH, Zhou YR, Zhang YJ, Yang X. Adenoassociated virus-mediated cancer gene therapy: current status. Cancer Lett. 2015;356(2):347-356.

6. Kim SU. Neural stem cell-based gene therapy for brain tumors. Stem Cell Rev Rep. 2011;7(1):130-140.

7. Chen LM, Sun JH, Yang XM. Radiofrequency ablation-combined multimodel therapies for hepatocellular carcinoma: current status. Cancer Lett. 2016;370(1):78-84.

8. Iwahashi S, Shimada M, Utsunomiya T, et al. Epithelial-mesenchymal transition-related genes are linked to aggressive local recurrence of hepatocellular carcinoma after radiofrequency ablation. Cancer Lett. 2016;375(1):47-50.

9. Gannon CJ, Patra CR, Bhattacharya R, Mukherjee P, Curley SA. Intracellular gold nanoparticles enhance non-invasive radiofrequency thermal destruction of human gastrointestinal cancer cells. J Nanobiotechnology. 2008;6:2.

10. Lauber K, Brix N, Ernst A, et al. Targeting the heat shock response in combination with radiotherapy: sensitizing cancer cells to irradiationinduced cell death and heating up their immunogenicity. Cancer Lett. 2015;368(2):209-229

11. Favarett A, Pasello G, Loreggian L, et al. Preoperative concomitant chemo-radiotherapy in superior sulcus tumour: a mono-institutional experience. Lung Cancer. 2010;68(2):228-233.

12. Jhaveri N, Agasse F, Armstrong D, et al. A novel drug conjugate, NEO212, targeting proneural and mesenchymal subtypes of patientderived glioma cancer stem cells. Cancer Lett. 2016;371(2):240-250.

13. Bernardes SS, de Souza-Neto FP, Ramalho LN, et al. Systemic oxidative profile after tumor removal and the tumor microenvironment in melanoma patients. Cancer Lett. 2015;361(1):226-232.

14. Wenk CH, Ponce F, Guillermet S, et al. Near-infrared optical guided surgery of highly infiltrative fibrosarcomas in cats using an anti- $\alpha_{v} \beta_{3}$ integrin molecular probe. Cancer Lett. 2013;334(2):188-195.

15. Kareva I, Waxman DJ, Klement GL. Metronomic chemotherapy: an attractive alternative to maximum tolerated dose therapy that can activate anti-tumor immunity and minimize therapeutic resistance. Cancer Lett. 2015;358(2):100-106.

16. Xin Y, Huang Q, Tang JQ, et al. Nanoscale drug delivery for targeted chemotherapy. Cancer Lett. 2016;379(1):24-31.

17. Blanco E, Hsiao A, Mann AP, Landry MG, Meric-Bernstam F, Ferrari M. Nanomedicine in cancer therapy: innovative trends and prospects. Cancer Sci. 2011;102(7):1247-1252.

18. D'Antonio C, Milano A, Righini R, et al. Pharmacogenomics in lung cancer chemotherapy: a review of what the oncologist should know. Anticancer Res. 2014;34(10):5241-5250.

19. Shabaruddin FH, Chen LC, Elliott RA, Payne K. A systematic review of utility values for chemotherapy-related adverse events. Pharmacoeconomics. 2013;31(4):277-288.

20. Bruheim K, Guren MG, Skovlund E, et al. Late side effects and quality of life after radiotherapy for rectal cancer. Int J Radiat Oncol. 2010; 76(4):1005-1011.

21. Salmenkylä S, Kouri M, Osterlund P, et al. Does preoperative radiotherapy with postoperative chemotherapy increase acute side-effects and postoperative complications of total mesorectal excision? Report of the randomized Finnish Rectal Cancer trial. Scand J Surg. 2012; 101(4):275-282.

22. Walker B Jr, Mouton CP. Nanotechnology and nanomedicine: a primer. J Natl Med Assoc. 2006;98(12):1985-1988.
23. Grudzien P, Lo S, Albain KS, et al. Inhibition of notch signaling reduces the stem-like population of breast cancer cells and prevents mammosphere formation. Anticancer Res. 2010;30(10):3853-3867.

24. Medina C, Santos-Martinez MJ, Radomski A, Corrigan OI, Radomski MW. Nanoparticles: pharmacological and toxicological significance. Br J Pharmacol. 2007;150(5):552-558.

25. Moghimi SM, Hunter AC, Murray JC. Nanomedicine: current status and future prospects. FASEB J. 2005;19(3):311-330.

26. Yu XH, Rong J, Zhan ZL, Liu Z, Liu JX. Effects of grain size and thermodynamic energy on the lattice parameters of metallic nanomaterials. Mater Des. 2015;83:159-163.

27. Kobayashi H, Ogawa M, Kosaka N, Choyke PL, Urano Y. Multicolor imaging of lymphatic function with two nanomaterials: quantum dotlabeled cancer cells and dendrimer-based optical agents. Nanomedicine (Lond). 2009;4(4):411-419.

28. Yoon TJ, Kim JS, Kim BG, Yu KN, Cho MH, Lee JK. Multifunctional nanoparticles possessing a "magnetic motor effect" for drug or gene delivery. Angew Chem Int Ed Engl. 2005;44(7):1068-1071.

29. Tang F, Li L, Chen D. Mesoporous silica nanoparticles: synthesis, biocompatibility and drug delivery. Adv Mater. 2012;24(12):1504-1534.

30. Manolova V, Flace A, Bauer M, Schwarz K, Saudan P, Bachmann MF. Nanoparticles target distinct dendritic cell populations according to their size. Eur J Immunol. 2008;38(5):1404-1413.

31. Ibanez IL, Notcovich C, Catalano PN, Bellino MG, Duran H. The redoxactive nanomaterial toolbox for cancer therapy. Cancer Lett. 2015; 359(1):9-19.

32. Liu L, Lv HY, Teng ZY, Wang CY, Wang GX. Glucose sensors based on core-shell magnetic nanomaterials and their application in diabetes management: a review. Curr Pharm Des. 2015;21(37):5359-5368.

33. Lv XN, Wang P, Bai R, et al. Inhibitory effect of silver nanomaterials on transmissible virus-induced host cell infections. Biomaterials. 2014; 35(13):4195-4203.

34. Fischer HC, Chan WC. Nanotoxicity: the growing need for in vivo study. Curr Opin Biotech. 2007;18(6):565-571.

35. Ahsan FL, Rivas IP, Khan MA, Suarez AI. Targeting to macrophages: role of physicochemical properties of particulate carriers-liposomes and microspheres-on the phagocytosis by macrophages. J Control Release. 2002;79(1-3):29-40.

36. Chithrani BD, Ghazani AA, Chan WC. Determining the size and shape dependence of gold nanoparticle uptake into mammalian cells. Nano Lett. 2006;6(4):662-668.

37. Champion JA, Katare YK, Mitragotri S. Particle shape: a new design parameter for micro- and nanoscale drug delivery carriers. $J$ Control Release. 2007;121(1-2):3-9.

38. Kaewsaneha C, Tangboriboonrat P, Polpanich D, Eissa M, Elaissari A. Janus colloidal particles: preparation, properties, and biomedical applications. ACS Appl Mater Interfaces. 2013;5(6):1857-1869.

39. Huang Y, Qi A, Han BH. Extraction of rutin and rhoifolin by inorganic borate functionalized magnetic particles. Chin J Chem. 2016;34(8): 823-829.

40. Cho K, Wang X, Nie S, Chen Z, Shin DM. Therapeutic nanoparticles for drug delivery in cancer. Clin Cancer Res. 2008;14(5):1310-1316.

41. De Jong WH, Borm PJ. Drug delivery and nanoparticles: applications and hazards. Int J Nanomedicine. 2008;3(2):133-149.

42. Hartman KB, Wilson LJ, Rosenblum MG. Detecting and treating cancer with nanotechnology. Mol Diagn Ther. 2008;12(1):1-14.

43. Cai W, Hsu AR, Li ZB, Chen X. Are quantum dots ready for in vivo imaging in human subjects? Nanoscale Res Lett. 2007;2(6):265-281.

44. Cai W, Chen X. Nanoplatforms for targeted molecular imaging in living subjects. Small. 2007;3(11):1840-1854.

45. Malmo J, Sandvig A, Vårum KM, Strand SP. Nanoparticle mediated P-glycoprotein silencing for improved drug delivery across the bloodbrain barrier: a siRNA-chitosan approach. PLoS One. 2013;8(1): e54182.

46. Mitchell LA, Lauer FT, Burchiel SW, McDonald JD. Mechanisms for how inhaled multiwalled carbon nanotubes suppress systemic immune function in mice. Nat Nanotechnol. 2009;4(7):451-456. 
47. Tkach AV, Shurin GV, Shurin MR, et al. Direct effects of carbon nanotubes on dendritic cells induce immune suppression upon pulmonary exposure. ACS Nano. 2011;5(7):5755-5762.

48. Mitchell LA, Gao J, Wal RV, Gigliotti A, Burchiel SW, McDonald JD. Pulmonary and systemic immune response to inhaled multiwalled carbon nanotubes. Toxicol Sci. 2007;100(1):203-214.

49. Liang HF, Chen CT, Chen SC, et al. Paclitaxel-loaded poly $(\gamma$-glutamic acid)-poly(lactide) nanoparticles as a targeted drug delivery system for the treatment of liver cancer. Biomaterials. 2006;27(9):2051-2059.

50. Zhu L, Huo Z, Wang L, Tong X, Xiao Y, Ni K. Targeted delivery of methotrexate to skeletal muscular tissue by thermosensitive magnetoliposomes. Int J Pharm. 2009;370(1-2):136-143.

51. Niidome T, Yamagata M, Okamoto Y, et al. PEG-modified gold nanorods with a stealth character for in vivo applications. J Control Release. 2006;114(3):343-347.

52. Shen S, Kong FF, Guo XM, et al. CMCTS stabilized $\mathrm{Fe}_{3} \mathrm{O}_{4}$ particles with extremely low toxicity as highly efficient near-infrared photothermal agents for in vivo tumor ablation. Nanoscale. 2013;5(17):8056-8066

53. Subbiah R, Veerapandian M, Yun KS. Nanoparticles: functionalization and multifunctional applications in biomedical sciences. Curr Med Chem. 2010;17(36):4559-4577.

54. Bronstein LM, Huang XL, Retrum J, et al. Influence of iron oleate complex structure on iron oxide nanoparticle formation. Chem Mater. 2007;19(15):3624-3632.

55. Schulz-Dobrick M, Sarathy KV, Jansen M. Surfactant-free synthesis and functionalization of gold nanoparticles. J Am Chem Soc. 2005;127(37): 12816-12817.

56. Chen JY, Wang DL, Xi JF, et al. Immuno gold nanocages with tailored optical properties for targeted photothermal destruction of cancer cells Nano Lett. 2007;7(5):1318-1322.

57. Lee SS, Zhu H, Contreras EQ, Prakash A, Puppala HL, Colvin VL. High temperature decomposition of cerium precursors to form ceria nanocrystal libraries for biological applications. Chem Mater. 2012; 24(3):424-432.

58. Hirsch LR, Stafford RJ, Bankson JA, et al. Nanoshell-mediated near-infrared thermal therapy of tumors under magnetic resonance guidance. Proc Natl Acad Sci U S A. 2003;100(23):13549-13554.

59. Matsumine A, Kusuzaki K, Matsubara T, et al. Novel hyperthermia for metastatic bone tumors with magnetic materials by generating an alternating electromagnetic field. Clin Exp Metastasis. 2007;24(3): 191-200.

60. Calero M, Chiappi M, Lazaro-Carrillo A, et al. Characterization of interaction of magnetic nanoparticles with breast cancer cells. J Nanobiotechnology. 2015;13:15.

61. Wuang SC, Neoh KG, Kang ET, Pack DW, Leckband DE. HER-2mediated endocytosis of magnetic nanospheres and the implications in cell targeting and particle magnetization. Biomaterials. 2008; 29(14):2270-2279.

62. Wahajuddin, Arora S. Superparamagnetic iron oxide nanoparticles: magnetic nanoplatforms as drug carriers. Int J Nanomedicine. 2012;7: 3445-3471.

63. Yang CY, Tai MF, Lin CP, et al. Mechanism of cellular uptake and impact of ferucarbotran on macrophage physiology. PLoS One. 2011; 6(9):e25524.

64. Liu G, Gao J, Ai H, Chen X. Applications and potential toxicity of magnetic iron oxide nanoparticles. Small. 2013;9(9-10):1533-1545.

65. Tang TY, Muller KH, Graves MJ, et al. Iron oxide particles for atheroma imaging. Arterioscler Throm Vasc Biol. 2009;29(7):1001-1008.

66. Eck W, Craig G, Sigdel A, et al. PEGylated gold nanoparticles conjugated to monoclonal F19 antibodies as targeted labeling agents for human pancreatic carcinoma tissue. ACS Nano. 2008;2(11):2263-2272.

67. Wilton-Ely JD. The surface functionalisation of gold nanoparticles with metal complexes. Dalton Trans. 2008;(1):25-29.

68. Zhang B, Chen JD, Zhu H, et al. Facile and green fabrication of size-controlled AuNPs/CNFs hybrids for the highly sensitive simultaneous detection of heavy metal ions. Electrochim Acta. 2016;196: $422-430$.
69. Brown SD, Nativo P, Smith JA, et al. Gold nanoparticles for the improved anticancer drug delivery of the active component of oxaliplatin. J Am Chem Soc. 2010;132(13):4678-4684.

70. Llevot A, Astruc D. Applications of vectorized gold nanoparticles to the diagnosis and therapy of cancer. Chem Soc Rev. 2012;41(1):242-257.

71. Wang JJ, Zeng ZW, Xiao RZ, et al. Recent advances of chitosan nanoparticles as drug carriers. Int J Nanomedicine. 2011;6:765-774.

72. Jokerst JV, Cole AJ, Van de Sompel D, Gambhir SS. Gold nanorods for ovarian cancer detection with photoacoustic imaging and resection guidance via Raman imaging in living mice. ACS Nano. 2012;6(11): 10366-10377.

73. Wang JJ, Zeng ZW, Xiao RZ, et al. Recent advances of chitosan nanoparticles as drug carriers. Int J Nanomedicine. 2011;6:765-774.

74. Verma A, Uzun O, Hu Y, et al. Surface-structure-regulated cell-membrane penetration by monolayer-protected nanoparticles. Nat Mater. 2008;7(7):588-595.

75. Laroui H, Rakhya P, Xiao B, Viennois E, Merlin D. Nanotechnology in diagnostics and therapeutics for gastrointestinal disorders. Dig Liver Dis. 2013;45(12):995-1002.

76. Fortina P, Kricka LJ, Graves DJ, et al. Applications of nanoparticles to diagnostics and therapeutics in colorectal cancer. Trends Biotechnol. 2007;25(4):145-152.

77. Sumbayev VV, Yasinska IM, Garcia CP, et al. Gold nanoparticles downregulate interleukin-1-induced pro-inflammatory responses. Small. 2013;9(3):472-477.

78. Chen H, Dorrigan A, Saad S, Hare DJ, Cortie MB, Valenzuela SM In vivo study of spherical gold nanoparticles: inflammatory effects and distribution in mice. PLoS One. 2013;8(2):e58208.

79. Walkey C, Das S, Seal S, et al. Catalytic properties and biomedical applications of cerium oxide nanoparticles. Environ Sci Nano. 2015; 2(1):33-53.

80. Pešić M, Podolski-Renić A, Stojković S, et al. Anti-cancer effects of cerium oxide nanoparticles and its intracellular redox activity. Chem Biol Interact. 2015;232:85-93.

81. Xiao YF, Li JM, Wang SM, et al. Cerium oxide nanoparticles inhibit the migration and proliferation of gastric cancer by increasing DHX15 expression. Int J Nanomedicine. 2016;11:3023-3034.

82. Akerman ME, Chan WC, Laakkonen P, Bhatia SN, Ruoslahti E. Nanocrystal targeting in vivo. Proc Natl Acad Sci US A. 2002;99(20): 12617-12621

83. Kim KY. Nanotechnology platforms and physiological challenges for cancer therapeutics. Nanomedicine. 2007;3(2):103-110.

84. Ballou B, Lagerholm BC, Ernst LA, Bruchez MP, Waggoner AS. Noninvasive imaging of quantum dots in mice. Bioconjug Chem. 2004; 15(1):79-86.

85. Morrow KJ Jr, Bawa R, Wei C. Recent advances in basic and clinical nanomedicine. Med Clin North Am. 2007;91(5):805-843.

86. Juzenas P, Chen W, Sun YP, et al. Quantum dots and nanoparticles for photodynamic and radiation therapies of cancer. Adv Drug Deliv Rev. 2008;60(15):1600-1614.

87. Ashcroft JM, Tsyboulski DA, Hartman KB, et al. Fullerene $\left(\mathrm{C}_{60}\right)$ immunoconjugates: interaction of water-soluble $\mathrm{C}_{60}$ derivatives with the murine anti-gp240 melanoma antibody. Chem Commun. 2006;(28): 3004-3006.

88. Prato M, Kostarelos K, Bianco A. Functionalized carbon nanotubes in drug design and discovery. Acc Chem Res. 2008;41(1):60-68.

89. Qiao R, Roberts AP, Mount AS, Klaine SJ, Ke PC. Translocation of $\mathrm{C}_{60}$ and its derivatives across a lipid bilayer. Nano Lett. 2007;7(3):614-619.

90. Satoh M, Takayanagi I. Pharmacological studies on fullerene $\left(\mathrm{C}_{60}\right)$, a novel carbon allotrope, and its derivatives. J Pharmacol Sci. 2006; 100(5):513-518.

91. Hirahara K, Suenaga K, Bandow S, et al. One-dimensional metallofullerene crystal generated inside single-walled carbon nanotubes. Phys Rev Lett. 2000;85(25):5384-5387.

92. Liang XJ, Meng H, Wang Y, et al. Metallofullerene nanoparticles circumvent tumor resistance to cisplatin by reactivating endocytosis Proc Natl Acad Sci U S A. 2010;107(16):7449-7454. 
93. Shvedova AA, Kisin ER, Porter D, et al. Mechanisms of pulmonary toxicity and medical applications of carbon nanotubes: two faces of Janus? Pharmacol Ther. 2009;121(2):192-204.

94. Terrones M, Terrones $H$. The carbon nanocosmos: novel materials for the twenty-first century. Philos Trans A Math Phys Eng Sci. 2003; 361(1813):2789-2806.

95. Lacerda L, Bianco A, Prato M, Kostarelos K. Carbon nanotubes as nanomedicines: from toxicology to pharmacology. Adv Drug Deliv Rev. 2006;58(14):1460-1470.

96. Karmakar A, Iancu C, Bartos DM, et al. Raman spectroscopy as a detection and analysis tool for in vitro specific targeting of pancreatic cancer cells by EGF-conjugated, single-walled carbon nanotubes. J Appl Toxicol. 2012;32(5):365-375.

97. Mahmood M, Karmakar A, Fejleh A, et al. Synergistic enhancement of cancer therapy using a combination of carbon nanotubes and antitumor drug. Nanomedicine (Lond). 2009;4(8):883-893.

98. Shen H, Ackerman AL, Cody V, et al. Enhanced and prolonged cross-presentation following endosomal escape of exogenous antigens encapsulated in biodegradable nanoparticles. Immunology. 2006; 117(1):78-88.

99. Heath JR, Davis ME. Nanotechnology and cancer. Annu Rev Med. 2008;59:251-265.

100. O’Neal DP, Hirsch LR, Halas NJ, Payne JD, West JL. Photo-thermal tumor ablation in mice using near infrared-absorbing nanoparticles. Cancer Lett. 2004;209(2):171-176.

101. Mocan L, Ilie I, Tabaran FA, et al. Surface plasmon resonance-induced photoactivation of gold nanoparticles as mitochondria-targeted therapeutic agents for pancreatic cancer. Expert Opin Ther Targets. 2013; 17(12):1383-1393.

102. Mocan L, Tabaran FA, Mocan T, et al. Selective ex-vivo photothermal ablation of human pancreatic cancer with albumin functionalized multiwalled carbon nanotubes. Int J Nanomedicine. 2011;6: 915-928.

103. Mocan T, Matea CT, Cojocaru I, et al. Photothermal treatment of human pancreatic cancer using PEGylated multi-walled carbon nanotubes induces apoptosis by triggering mitochondrial membrane depolarization mechanism. J Cancer. 2014;5(8):679-688.

104. Kam NW, O’Connell M, Wisdom JA, Dai HJ. Carbon nanotubes as multifunctional biological transporters and near-infrared agents for selective cancer cell destruction. Proc Natl Acad Sci U S A. 2005; 102(33):11600-11605.

105. Shao N, Lu S, Wickstrom E, Panchapakesan B. Integrated molecular targeting of IGF1R and HER2 surface receptors and destruction of breast cancer cells using single wall carbon nanotubes. Nanotechnology. 2007; 18(31):315101.

106. Biris AS, Boldor D, Palmer J, et al. Nanophotothermolysis of multiple scattered cancer cells with carbon nanotubes guided by time-resolved infrared thermal imaging. J Biomed Opt. 2009;14(2):021007.

107. Burlaka A, Lukin S, Prylutska S, et al. Hyperthermic effect of multiwalled carbon nanotubes stimulated with near infrared irradiation for anticancer therapy: in vitro studies. Exp Oncol. 2010;32(1): 48-50.

108. Novoselov KS, Geim AK, Morozov SV, et al. Electric field effect in atomically thin carbon films. Science. 2004;306(5696):666-669.

109. Rao CN, Sood AK, Subrahmanyam KS, Govindaraj A. Graphene: the new two-dimensional nanomaterial. Angew Chem Int Ed Engl. 2009; 48(42):7752-7777

110. Allen MJ, Tung VC, Kaner RB. Honeycomb carbon: a review of graphene. Chem Rev. 2010;110(1):132-145.

111. Yang K, Feng LZ, Shi XZ, Liu Z. Nano-graphene in biomedicine: theranostic applications. Chem Soc Rev. 2013;42(2):530-547.

112. Yang K, Hu LL, Ma XX, et al. Multimodal imaging guided photothermal therapy using functionalized graphene nanosheets anchored with magnetic nanoparticles. Adv Mater. 2012;24(14):1868-1872.

113. Yang K, Zhang SA, Zhang GX, Sun XM, Lee ST, Liu ZA. Graphene in mice: ultrahigh in vivo tumor uptake and efficient photothermal therapy. Nano Lett. 2010;10(9):3318-3323.
114. Yang K, Wan JM, Zhang S, Tian B, Zhang YJ, Liu Z. The influence of surface chemistry and size of nanoscale graphene oxide on photothermal therapy of cancer using ultra-low laser power. Biomaterials. 2012;33(7):2206-2214.

115. Zedan AF, Moussa S, Terner J, Atkinson G, El-Shall MS. Ultrasmall gold nanoparticles anchored to graphene and enhanced photothermal effects by laser irradiation of gold nanostructures in graphene oxide solutions. ACS Nano. 2013;7(1):627-636.

116. Dembereldorj U, Choi SY, Ganbold EO, et al. Gold nanorod-assembled PEGylated graphene-oxide nanocomposites for photothermal cancer therapy. Photochem Photobiol. 2014;90(3):659-666.

117. Shi JJ, Wang L, Zhang J, et al. A tumor-targeting near-infrared lasertriggered drug delivery system based on GO@Ag nanoparticles for chemo-photothermal therapy and X-ray imaging. Biomaterials. 2014; 35(22):5847-5861.

118. Bai J, Liu YW, Jiang XE. Multifunctional PEG-GO/CuS nanocomposites for near-infrared chemo-photothermal therapy. Biomaterials. 2014;35(22):5805-5813.

119. Hou CY, Quan HC, Duan YR, Zhang QH, Wang HZ, Li YG. Facile synthesis of water-dispersible $\mathrm{Cu}_{2} \mathrm{O}$ nanocrystal-reduced graphene oxide hybrid as a promising cancer therapeutic agent. Nanoscale. 2013;5(3):1227-1232.

120. Friedhuber AM, Chandolu V, Manchun S, Donkor O, Sriamornsak P, Dass CR. Nucleotropic doxorubicin nanoparticles decrease cancer cell viability, destroy mitochondria, induce autophagy and enhance tumour necrosis. J Pharm Pharmacol. 2015;67(1):68-77.

121. Shi SF, Jia JF, Guo XK, et al. Biocompatibility of chitosan-coated iron oxide nanoparticles with osteoblast cells. Int J Nanomedicine. 2012; 7:5593-5602.

122. Upadhyaya L, Singh J, Agarwal V, Tewari RP. Biomedical applications of carboxymethyl chitosans. Carbohydr Polym. 2013;91(1): 452-466

123. Bodnar M, Hartmann JF, Borbely J. Preparation and characterization of chitosan-based nanoparticles. Biomacromolecules. 2005;6(5): 2521-2527.

124. Goldberg M, Langer R, Jia X. Nanostructured materials for applications in drug delivery and tissue engineering. J Biomater Sci Polym Ed. 2007;18(3):241-268.

125. Amidi M, Mastrobattista E, Jiskoot W, Hennink WE. Chitosan-based delivery systems for protein therapeutics and antigens. Adv Drug Deliv Rev. 2010;62(1):59-82.

126. Bawarski WE, Chidlowsky E, Bharali DJ, Mousa SA. Emerging nanopharmaceuticals. Nanomedicine. 2008;4(4):273-282.

127. Seferian PG, Martinez ML. Immune stimulating activity of two new chitosan containing adjuvant formulations. Vaccine. 2000;19(6): 661-668.

128. Shibata Y, Foster LA, Metzger WJ, Myrvik QN. Alveolar macrophage priming by intravenous administration of chitin particles, polymers of n-acetyl-d-glucosamine, in mice. Infect Immun. 1997;65(5): 1734-1741.

129. Calvo P, Remuñan-López C, VilaJato JL, Alonso MJ. Chitosan and chitosan ethylene oxide propylene oxide block copolymer nanoparticles as novel carriers for proteins and vaccines. Pharm Res. 1997;14(10): 1431-1436.

130. Jeong YI, Jin SG, Kim IY, et al. Doxorubicin-incorporated nanoparticles composed of poly(ethylene glycol)-grafted carboxymethyl chitosan and antitumor activity against glioma cells in vitro. Colloids Surf B Biointerfaces. 2010;79(1):149-155.

131. Kostarelos K, Bianco A, Prato M. Promises, facts and challenges for carbon nanotubes in imaging and therapeutics. Nat Nanotechnol. 2009;4(10):627-633

132. Zhang WX, Karn B. Nanoscale environmental science and technology: challenges and opportunities. Environ Sci Technol. 2005; 39(5):94A-95A.

133. Lanone S, Boczkowski J. Biomedical applications and potential health risks of nanomaterials: molecular mechanisms. Curr Mol Med. 2006;6(6):651-663. 
134. Hoshino A, Hanada S, Yamamoto K. Toxicity of nanocrystal quantum dots: the relevance of surface modifications. Arch Toxicol. 2011; 85(7):707-720

135. Proffitt F. Yellow light for nanotech. Science. 2004;305(5685): $762-765$.

136. Lam CW, James JT, McCluskey R, Hunter RL. Pulmonary toxicity of single-wall carbon nanotubes in mice 7 and 90 days after intratracheal instillation. Toxicol Sci. 2004;77(1):126-134.

137. Service RF. Nanotechnology grows up. Science. 2004;304(5678): 1732-1734.

138. Lam CW, James JT, McCluskey R, Arepalli S, Hunter RL. A review of carbon nanotube toxicity and assessment of potential occupational and environmental health risks. Crit Rev Toxicol. 2006;36(3):189-217.

139. Nel A, Xia T, Madler L, Li N. Toxic potential of materials at the nanolevel. Science. 2006;311(5761):622-627.

140. Manna SK, Sarkar S, Barr J, et al. Single-walled carbon nanotube induces oxidative stress and activates nuclear transcription factor- $\mathrm{KB}$ in human keratinocytes. Nano Lett. 2005;5(9):1676-1684.

141. Ravichandran P, Baluchamy S, Sadanandan B, et al. Multiwalled carbon nanotubes activate NF- $\mathrm{KB}$ and AP-1 signaling pathways to induce apoptosis in rat lung epithelial cells. Apoptosis. 2010;15(12): $1507-1516$
142. Cui DX, Tian FR, Ozkan CS, Wang M, Gao HJ. Effect of single wall carbon nanotubes on human HEK293 cells. Toxicol Lett. 2005; 155(1):73-85.

143. Renwick LC, Brown D, Clouter A, Donaldson K. Increased inflammation and altered macrophage chemotactic responses caused by two ultrafine particle types. Occup Environ Med. 2004;61(5):442-447.

144. Li H, Chen Q, Han BH. Sugar-functionalized triptycenes used for dispersion of single-walled carbon nanotubes in aqueous solution by supramolecular interaction. New J Chem. 2016;40(4):3300-3307.

145. Barzegar A, Mansouri A, Azamat J. Molecular dynamics simulation of non-covalent single-walled carbon nanotube functionalization with surfactant peptides. J Mol Graph Model. 2016;64:75-84.

146. Ali K, Mahmoud WE. Development of functionalized single walled carbon nanotubes based triacylglycerol acylhydrolases. Synth Met. 2013;175:52-55.

147. Firme CP 3rd, Bandaru PR. Toxicity issues in the application of carbon nanotubes to biological systems. Nanomedicine. 2010;6(2): 245-256.
International Journal of Nanomedicine

\section{Publish your work in this journal}

The International Journal of Nanomedicine is an international, peerreviewed journal focusing on the application of nanotechnology in diagnostics, therapeutics, and drug delivery systems throughout the biomedical field. This journal is indexed on PubMed Central, MedLine, CAS, SciSearch $®$, Current Contents $\AA /$ Clinical Medicine,

\section{Dovepress}

Journal Citation Reports/Science Edition, EMBase, Scopus and the Elsevier Bibliographic databases. The manuscript management system is completely online and includes a very quick and fair peer-review system, which is all easy to use. Visit http://www.dovepress.com/ testimonials.php to read real quotes from published authors. 